\title{
Graphical Connection Priming and Ethics: as Our Sense of Human Connection Decreases, so too Does Our Ethical Decision-Making
}

\author{
Chris Macdonald ${ }^{1 *}$ \\ ${ }^{1}$ Skylab, United Kingdom \\ *Corresponding author: Chris Macdonald: chrismacdonald@dr.com
}

\section{OPEN ACCESS}

Citation: Macdonald C. (2020) Graphical Connection Priming and Ethics: as Our Sense of Human Connection Decreases, so too Does Our Ethical Decision-Making. Open Science Journal 5(1)

Received: $14^{\text {th }}$ December 2019

Accepted: $5^{\text {th }}$ March 2020

Published: 23 ${ }^{\text {rd }}$ March 2020

Copyright: (c) 2020 This is an open access article under the terms of the Creative Commons Attribution License, which permits unrestricted use, distribution, and reproduction in any medium, provided the original author and source are credited.

Funding: The author received no specific funding for this work

Competing Interests: The author has declared that no competing interests exist.

\begin{abstract}
:
From road rage to youtube comments, there are indications all around us that when there is some form of human disconnect, we are far from the best versions of ourselves. A recent paper revealed that the mere thought of human disconnection can weaken our morals. This paper reveals three new experiments that further explore this phenomenon. The results of experiments 1 and 2 show that an increase of unethical decision-making can be triggered via simple imagery of stickmen separated from one another. Experiment 3 suggests that the phenomenon might also be triggered with simple geometric imagery depicting the disconnection of $2 \mathrm{D}$ shapes.
\end{abstract}

Keywords: Ethics, Connection, Images, Communications, Disconnecting agents, Psychology, Sociology, Economics, Priming

\section{Introduction}

There are several classic experiments that you are likely to come across if you are a student of psychology, two of which are the Robbers Cave Experiment (Sherif et al, 1961), and perhaps even more well known, the infamous, Milgram Experiment (Milgram, 1963). What links the two is that they both demonstrate the potent danger of disconnection.

In the Robbers Cave Experiment, a group of 22 young boys was separated into two teams at a summer camp (Pennington, 2000). Although the groups were artificially created, and randomly assigned, the boys began to strongly identify with them. In week two, the researchers made the groups aware of each other. They then organized a series of games where the two groups would have to compete (such as a football match and a game of baseball). While the boys had 
previously been well-behaved, there was now conflict between the two camps. As tension continued to rise, name-calling turned to vandalism, which escalated to theft and even physical violence before the researchers had to step in (Chua, 2018). In order to regain civility, the researchers created fake situations whereby the groups had to collaborate to solve issues that clearly impacted them both, such as an issue with the camp's food and water supply (Brain, 2000). The more connections they found, through solving common problems and socializing, the more they began the behave ethically.

In the Milgram Experiment, participants were asked to administer an electric shock to a learner each time they got an answer wrong. While the participant thought they were part of a study exploring learning methods, they were actually the subjects of another experiment, and everyone else involved were actors. Each time the 'learner' got a response wrong, the participant was asked to administer a shock and then increase the voltage. The real study, therefore, explored how much someone would be willing to cause pain to another as a result of being told to do so by an authority figure. The study showed that the majority of participants administered the maximum level of (what they believed to be) 450 volts, despite the 'learners' crying out in pain - a finding that deeply surprised Milgrim himself (Blass, 2000; Blass, 2009).

Milgram went on to complete many variations of the experiment which revealed that disconnection plays an important role (Milgram, 1974). When the participants were physically closer to the 'learner', the majority of them refused to administer a shock and instead chose to abandon the experiment (Milgram, 1974).

Both of these infamous studies indicate that increased human connection can lead to more ethical decisions, and decreased human connections can lead to more unethical decisions. While these experiments explored connection and disconnection through physical variations, what about the mere idea of connection or disconnection? Could this also influence ethical decision-making? And could it be triggered via imagery?

To the extent of my knowledge, there hasn't been experimentation that explicitly tests if one can trigger a sense of human connection or disconnection via images alone and if this would be sufficient to impact one's ethical decisionmaking.

\section{Experiment 1}

It has previously been shown that when participants were primed with disconnection themes they were less ethical than those who were primed with connection themes (Macdonald, 2019). The priming strategies used in the aforementioned study included a combination of ten detailed word-based tasks and five image tasks. In Experiment 1, I wanted to see if I would replicate this finding when priming with image tasks alone.

\section{Participants.}

100 UK Students took part in the experiment. In an attempt to reduce variables, all participants had the following in common: aged 18-25, caucasian ethnicity, and English-only spoken at home. 


\section{Procedure.}

Participants were randomly assigned to one of two groups: Connection Prime (CN), and Disconnection Prime (D) (50 participants per group). Each group was given 10 simple image tasks relevant to their prime.

All of CN's images contained stickmen (simple line drawings of the human form) connected together. All of D's images contained stickmen separated by borders. The task involved counting the number of 'people' per image.

After both groups had completed their priming tasks, they were given the same set of 8 ethically relevant scenarios and were asked to indicate on a 7 point scale how likely it would be for them to engage in the behavior described $(1=$ not at all likely, $7=$ highly likely).

Therefore, the mean of the groups will be a number from 1 to 7 , and due to the nature of the questions and their framing, a lower score would be deemed as more ethical.

The scenarios and rating scale have been used in prior experiments (Piff et al, 2012; Kouchaki et al, 2013; Macdonald, 2019) and have been validated in several ways (Piff et al, 2012).

\section{Results.}

In accordance with previous findings (Macdonald, 2019), the data revealed that those primed with human disconnection $(\mathrm{M}=4.34, \mathrm{SD}=2.19, \mathrm{~N}=50)$ indicated that they were more likely to engage in the described unethical behavior than those who were primed with human connection $(\mathrm{M}=4.26, \mathrm{SD}=$ $2.14, \mathrm{~N}=50), \mathrm{t}(97)=-0.43, \mathrm{p}=.6$. This further supports the hypothesis that a decreased sense of human connection can have a negative impact on ethical decisions. The results also suggest that this phenomenon can be triggered via simple imagery.

An area for improvement with this experiment is the level of consistency of the images between the two groups. For example, although the size, colour, and style of the stickmen were identical, the total amount of stickmen and their relative positioning wasn't exactly the same across both sets of images; this was a byproduct of the way in which the sense of connection was depicted.

\section{Experiment 2}

The goal of Experiment 2 was to further test the hypothesis while reducing the variables between the two groups. Therefore an alternative representation of connection was used: rather than the connection point being a 'hand', it was now a line. This enabled a greater distance between the stickmen while still maintaining the idea of connection. With this update, the number of elements to count and their placement and orientation was consistent across groups, thus reducing unintended variables. 


\section{Participants.}

100 UK Students took part in the experiment. In an attempt to reduce variables, all participants had the following in common: aged 18-25, caucasian ethnicity, and English-only spoken at home.

\section{Procedure.}

As with Experiment 1, the 100 participants were randomly assigned to one of two groups: Connection Prime $(\mathrm{CN})$, and Disconnection Prime (D) (50 participants per group). Each group was given 10 simple image tasks relevant to their prime.

All of CN's images contained stickmen connected by lines. All of D's images contained stickmen separated by borders. The task involved counting the number of 'people' per image.

The participants were then given the same ethics test as used in Experiment 1 (a lower score is deemed as more ethical).

\section{Results.}

In accordance with previous findings (Macdonald, 2019), and Experiment 1, the data revealed that those primed with human disconnection $(\mathrm{M}=4.28, \mathrm{SD}=$ 2.10, $\mathrm{N}=50$ ) were less ethical when compared to those primed with human connection $(\mathrm{M}=4.10, \mathrm{SD}=2.17, \mathrm{~N}=50)$.

The difference between the two groups was more significant when compared to Experiment $1, \mathrm{t}(96)=-0.81, \mathrm{p}=.4$.

\section{Experiment 3}

Both prior studies (Macdonald, 2019), and experiments 1 and 2 reported here, indicate that an underlying mechanism behind unethical decision-making may be a feeling of human disconnection. To further explore this phenomenon, I wanted to test whether priming a general sense of disconnection would have the same effect. Perhaps it is not necessarily human disconnection but the broader concept of disconnection itself. Therefore, potentially, the phenomenon could be triggered without depictions of the human form.

\section{Participants.}

100 UK Students took part in the experiment. In an attempt to reduce variables all participants had the following in common: aged 18-25, caucasian ethnicity, and English-only spoken at home.

*A note on the participants.

Although the demographics were consistent across all three experiments, none of the participants were allowed to partake in more than one experiment. That is 
to say that as there were 100 participants in each experiment, there were 300 unique participants in total.

\section{Procedure.}

As with the previous experiments, the participants were randomly assigned to one of two groups: Connection Prime (CN), and Disconnection Prime (D) (50 participants per group). Each group was given a set of 10 image tasks relevant to their prime. CN's images contained a series of circles connected with lines. D's images contained circles separated by borders. The task involved counting the number of circles per image.

To maintain consistency between the two groups, the number of circles was consistent, as was their size, and positioning. The formatting of Experiment 3's images was consistent with those of Experiment 2. That is to say that the only thing that has changed with the image primes between experiments 2 and 3 , was that the items to count are now circles rather than stickmen; the lines or borders, and positioning of the elements remained the same.

\section{Results.}

Consistent with the previous findings, those primed with images depicting disconnection ( $\mathrm{M}=4.24, \mathrm{SD}=2.17, \mathrm{~N}=50)$ were less ethical when compared to those primed with images depicting connection $(\mathrm{M}=4.19, \mathrm{SD}=2.08, \mathrm{~N}=50)$. However, the difference between $\mathrm{CN}$ and $\mathrm{D}$ was not as significant as the previous experiments, $\mathrm{t}(92)=-0.25, \mathrm{p}=.8$. Therefore the findings suggest that priming a sense of human disconnection is a more potent prime than priming a more general sense of disconnection - with regard to the impact on ethical decisionmaking.

\section{Concluding Remarks}

While there is still much exploration to be done within this field, the findings reported here appear to indicate that in addition to physical disconnection (e.g. Milgram and Robbers Cave), the mere image of human disconnection can negatively impact our ethical decision-making. Therefore, while we should study the consequences of technologies that can decrease authentic human connectiononline shopping, pornography, gaming, 'social' media - perhaps we should also be studying more abstract forms of human disconnection: ideas, terms, and even simple images.

It is important for us to remember that we are particularly vulnerable when disconnected from each other, and that we are also particularly susceptible to various means of disconnection. 


\section{References:}

Blass T. 2000. Obedience to Authority: Current Perspectives on the Milgram Paradigm, Lawrence Erlbaum Associates: Mahwah, New Jersey

Blass T. 2009. The Man Who Shocked The World, Basic Books: New York

Brain C. 2000. Advanced Subsidiary Psychology, Cheltenham: Nelson Thornes Ltd

Chua A. 2018. Political Tribes, Group instinct and the fate of nations, Penguin Press: New York

Kouchaki M, Smith-Crowe K, Brief AP, Sousa C. 2013. Seeing green: Mere exposure to money triggers a business decision frame and unethical outcomes. Organizational Behaviour Human Decision Processes 121:(1) 53-61

Macdonald C. 2019. Money, a disconnecting agent: Reminders of money trigger a feeling of disconnection which increases the likelihood of unethical decisions. Open Science Journal, 4:(1) 110

Milgram S. 1963. Behavioral Study of obedience. The Journal of Abnormal and Social Psychology, 67:(4) 371-378

Milgram S. 1974. Obedience to Authority: An Experimental View, London: Tavistock Publications

Pennington DC. 2000. Social Cognition, Routledge: Philadelphia

Piff PK, Stancato DM, Côté S, Mendoza-Denton R, Keltner D. 2012. Higher social class predicts increased unethical behavior. Proceedings of the National Academy of Sciences 109:(11) 40864091

Sherif M, Harvey OJ, White BJ, Hood WE, Sherif, CS. 1961. Intergroup conflict and cooperation: The Robbers Cave experiment. Norman: University of Oklahoma Book Exchange 